\title{
Renal Involvement in Rhupus Syndrome: A Case Report
}

\author{
Jaouad Yousfi ${ }^{{ }^{*}}$, Soukaina Oumlil ${ }^{1}$, Laila Benjilali ${ }^{1}$, Lamiaa Essaadouni ${ }^{1}$ \\ ${ }^{1}$ Department of Internal Medicine, University Hospital of Mohammed VI, Marrakesh, Morocco
}

DOI: 1 10.36348/sjm.2021.v06i03.001 | | Received: 22.02.2021 | Accepted: 03.03.2021 | Published: 15.03 .2021

*Corresponding Author: Dr. Jaouad Yousfi

\section{Abstract}

Rheumatoid arthritis is chronic rheumatism characterized by symmetric, inflammatory, peripheral polyarthritis with a highly destructive potential. Systemic lupus erythematosus is a multi-system autoimmune disease that combines visceral involvement with very frequent and disabling joint damage. These two pathologies share many clinical manifestations and may coexist in a patient. Such condition defines the Rhupus syndrome, which is a rare overlapping syndrome. The exact etiopathogenesis remains unknown. Serious visceral damages, particularly renal, are exceptionally reported during Rhupus syndrome. We report the case of a male patient diagnosed with Rhupus syndrome who presented with glomerulonephritis.

Keywords: Rhupus, etiopathogenesis.

Copyright (C) 2021 The Author(s): This is an open-access article distributed under the terms of the Creative Commons Attribution 4.0 International License (CC BY-NC 4.0) which permits unrestricted use, distribution, and reproduction in any medium for non-commercial use provided the original author and source are credited.

\section{INTRODUCTION}

The coexistence of two or more connective tissue diseases in the same patient is a rare phenomenon, particularly the combination of rheumatoid arthritis (RA) and systemic lupus erythematosus (SLE). This association was first described by Toone in 1960, however it was Shur in 1971 who first used the term "Rhupus" to refer to it [1, $2]$.

Rhupus syndrome is a rare clinical entity [3, 4]. Its prevalence is around $0.09 \%$ [3], with few isolated case reports. Renal involvement during this syndrome is rarely described in the literature (Table 1). We report the case of a glomerulonephritis complicating Rhupus syndrome in a 35 -year-old man.

\section{CASE PRESENTATION}

A 35-year-old man, diagnosed with seropositive RA on the basis of symmetrical polyarthritis involving the large and small joints, sparing the distal interphalangeal joints. Physical examination showed typical RA osteoarticular deformities including ulnar drift, swan-neck and Zshaped deformities. Standard radiography showed erosive lesions with left wrist carpitis. He tested positive for rheumatoid factor (Waler-rose at $65 \mathrm{IU} / \mathrm{ml}$, and latex at $80 \mathrm{IU} / \mathrm{ml}$ ) and for anti-cyclic citrullinated peptide antibodies (99 IU/ml). He was treated with corticosteroids (prednisone $10 \mathrm{mg}$ daily) and methotrexate (15 mg weekly).

Two years after the initial RA diagnosis, the patient presented with a NYHA Class III dyspnea associated with asthenia and photosensitivity. Physicalfindings were consistent with pleural effusion. His laboratory results revealed lymphopenia of $250 /$ $\mathrm{mm}^{3}$ with regenerative normochromic normocytic anemia at $8 \mathrm{~g} / \mathrm{dl}$ and a positive coombs test. Serum antinuclear antibodies were positive with a titer of $1 / 640$ with a homogeneous pattern. He also tested positive for anti-dsDNA (39 IU/ml) and anti-Sm antibodies.

Kidney function was abnormal with a serum creatinine of $14,8 \mathrm{mg} / \mathrm{l}$, urea of $0,9 \mathrm{~g} / \mathrm{l}$, and the estimated glomerular filtration rate was at $57,3 \mathrm{ml} / \mathrm{min}$ $11.73 \mathrm{~m}^{2}$. The urine sediment examination revealed hematuria without leukocyturia. The proteinuria was positive at $2.54 \mathrm{~g} / 24 \mathrm{~h}$. Cardiac ultrasound and chest Xray showed moderate pleuropericarditis.

The diagnosis of rhupussyndrome was established of the basis of SLE and RA criteria. A kidney biopsy was performed, revealing class IV lupus nephritis with deposits of $\operatorname{IgA}, \operatorname{IgM}, \operatorname{IgG}, \mathrm{C} 3$ and C1q.

He received three consecutive pulses of methylprednisolone $1000 \mathrm{mg}$ IV daily, followed by oral prednisone (1 $\mathrm{mg} / \mathrm{kg} / \mathrm{day})$, IV cyclophosphamide 
Jaouad Yousfi et al.; Saudi J Med, Mar, 2021; 6(3): 57-59

monthly for 6 months and every 3 months for 2 years, then azathioprine at $150 \mathrm{mg} / \mathrm{day}$.

The patient achieved renal and articular remission with proteinuria of $0.2 \mathrm{~g} / 24 \mathrm{~h}$. No recurrence was observed during a 4-year follow-up.

\section{DISCUSSION}

Rhupus syndrome is a rare entity with an estimated prevalence of $0,09 \%(5)$. It is an overlap syndrome with no consensus over definition, diagnosis and treatment [6].

RA and SLE have long been considered as two mutually-exclusive systemic autoimmune diseases with radically different epidemiological, pathophysiological, clinical and biological profiles and treatments, as RA involves a Th1 response, while there is shift toward a Th2 response in patients with SLE, with two different genetic backgrounds [7].

In 1971, Peter Shur introduced the concept of Rhupus, he coined the term "rhupus" to describe patients who satisfy the criteria for both SLE and RA [1]. Panush and colleagues accurately described six patients with RA and SLE simultaneously in 1988. They concluded that Rhupus was linked to an erosive arthritis in lupus patients [3].

Although anti-cyclic citrullinated peptide antibodies and rheumatoid factor may exceptionally be present in lupus, their high levels (greater than 3 times the upper limit of normal) and the presence of early radiologic signs are clear evidence of an authentic RA, and predictive marker of worse functional prognosis.
On the other hand, the simultaneous positivity of native anti-dsDNA and anti-Sm antibodies supports the diagnosis of an overlapping lupus, thus constituting rhupus syndrome.

The initial clinical symptoms most often correspond to those of RA, followed by those of SLE. In order of frequency, the clinical manifestations of lupus are cutaneous, hematological and serosal, with a mean onset time of 11 years $[7,8]$.

Few authors have encountered renal involvement in cases of Rhupus syndrome presenting with lupus nephritis (Table 1). In a retrospective study including 7 cases with rhupus syndrome, Pichilingue et al., reported aclass IV glomerulonephritis in 5 patients, with aproteinuria varying between 288 et $2560 \mathrm{mg} / \mathrm{day}$. it seems then that renal involvementduringrhupus syndrome is severe, as it was also the case of our patient [9].

To date, there is no consensus on recommendations for the management of rhupus syndrome. Corticosteroid therapy combined with methotrexate or synthetic antimalarial drugs have shown their effectiveness [6, 10]. R. Seohad used Cyclosporine with good results after six months [11].

\section{CONCLUSION}

Rhupus syndrome is a rare condition characterized by the presence of erosive arthritis together with signs of SLE.Renal involvement complicates its prognosis; it is rare with very limited reported cases.

Table-1: Published cases of renal involvement in rhupus syndrome

\begin{tabular}{|c|c|c|}
\hline Author & Patients number & Renal involvement \\
\hline Li J et al.[12) & 56 & 22 patients \\
\hline Liu et al. [13] & 51 & 29 patients \\
\hline Frade-Sosa et al. [14] & 40 & 4 patients \\
\hline Simon et al. [15] & 22 & 5 patients \\
\hline Cohen et al. [8] & 11 & 8 patients \\
\hline Brand et al. [16] & 11 & 7 patients \\
\hline Tani et al. [17] & 10 & 2 patients \\
\hline Fernandez et al. [18] & 8 & 3 patients \\
\hline Martinez et al. [19] & 8 & 3 patients \\
\hline Pichilingue et al. [9] & 7 & 5 patients (type IV glomerulonephritis) \\
\hline Panush et al. [3] & 6 & 1 patient \\
\hline Benavente et al. [20] & 4 & 1 patient \\
\hline Roy et al. [21] & 1 & Class IV lupus nephritis \\
\hline Zhao XJ et al. [22] & 1 & Lupus nephritis \\
\hline Santos et al. [23] & 1 & Class V lupus nephritis \\
\hline
\end{tabular}

\section{REFERENCES}

1. Schur, P. H. (1971). Systemic lupus erythematosus in Cecil-Loeb Texbook of Medicine. Philadelphia, PA, 821.
2. Toone Jr, E. C., \& EL, P. (1960). The LE cell in rheumatoid arthritis. The American journal of the medical sciences, 240, 599-608. 
Jaouad Yousfi et al.; Saudi J Med, Mar, 2021; 6(3): 57-59

3. Panush, R. S., Edwards, N. L., Longley, S., \& Webster, E. (1988). 'Rhupus' syndrome. Archives of Internal Medicine, 148(7), 1633-1636.

4. Navarro, J. E., \& Garcia, I. (1988). Associacio de artritis reumatoide y lupus eritematoso generalizado. Rev Mex Reumatol, 3, 138-140.

5. Sarkar, S., \& Saha, K. (2012). Bilateral acute lupus pneumonitis in a case of rhupus syndrome. Lung India: Official Organ of Indian Chest Society, 29(3), 280.

6. Devrimsel, G., \& Serdaroglu Beyazal, M. (2018). Three Case Reports of Rhupus Syndrome: An Overlap Syndrome of Rheumatoid Arthritis and Systemic Lupus Erythematosus. Case reports in rheumatology, 2018.

7. Malaise, O., Halleux, S., VAN FRENCKELL, C., Lutteri, L., \& CHAPELLE, J. P. (2012). LE RHUPUS: à la frontière entre polyarthrite rhumatoïde et lupus érythémateux disséminé. RMLG. Revue médicale de Liège, 67(9).

8. Cohen, M. G., \& Webb, J. O. H. N. (1987). Concurrence of rheumatoid arthritis and systemic lupus erythematosus: report of 11 cases. Annals of the rheumatic diseases, 46(11), 853-858.

9. Pichilingue, G. S., Campos, J. G., \& Zevallos, J. C. (2011). Características clínicas y hallazgos histopatológicos de glomerulonefritis lúpica en pacientes con Rhupus en el Hospital Nacional Arzobispo Loayza en los años 2003 al 2009. Acta Médica Peruana, 28(2), 79-81.

10. Hachicha, I., Fourati, H., Akrout, R., \& Baklouti, S. (2012). Rhupus syndrome: report of two cases. The Pan African medical journal, 12, 50-50.

11. Seo, S. R., Lee, S. J., Park, D. J., Kim, T. J., Park, Y. W., \& Lee, S. S. (2011). Successful treatment using cyclosporine in a patient with rhupus complicated by aplastic anemia: a case report and review of the literature. Clinical and experimental rheumatology, 29(4), 708-711.

12. Li, J., Wu, H., Huang, X., Xu, D., Zheng, W., Zhao, Y., ... \& Zeng, X. (2014). Clinical analysis of 56 patients with rhupus syndrome: manifestations and comparisons with systemic lupus erythematosus: a retrospective case-control study. Medicine, 93(10).

13. Liu, T., Li, G., Mu, R., Ye, H., Li, W., \& Li, Z. (2014). Clinical and laboratory profiles of rhupus syndrome in a Chinese population: a single-centre study of 51 patients. Lupus, 23(9), 958-963.

14. Frade-Sosa, B., Narváez, J., Salman-Monte, T. C., Castellanos-Moreira, R., Ortiz-Santamaria, V.,
Torrente-Segarra, V., ... \& Gómez-Puerta, J. A. (2020). A comparative study on clinical and serological characteristics between patients with rhupus and those with systemic lupus erythematosus and rheumatoid arthritis. Lupus, 29(10), 1216-1226.

15. Simon, J. A., Granados, J., Cabiedes, J., Morales, J. R., \& Varela, J. A. (2002). Clinical and immunogenetic characterization of Mexican patients with 'rhupus'. Lupus, 11(5), 287-292.

16. Brand, C. A., Rowley, M. J., Tait, B. D., Muirden, K. D., \& Whittingham, S. F. (1992). Coexistent rheumatoid arthritis and systemic lupus erythematosus: clinical, serological, and phenotypic features. Annals of the rheumatic diseases, 51(2), 173-176.

17. Tani, C., D'Aniello, D., Delle Sedie, A., Carli, L., Cagnoni, M., Possemato, N., ... \& Mosca, M. (2013). Rhupus syndrome: assessment of its prevalence and its clinical and instrumental characteristics in a prospective cohort of 103 SLE patients. Autoimmunity reviews, 12(4), 537-541.

18. Fernández, A., Quintana, G., Rondón, F., Restrepo, J. F., Sánchez, A., Iglesias, A., \& Matteson, E. L. (2006). Lupus arthropathy: a case series of patients with rhupus. Clinical rheumatology, 25(2), 164167.

19. Martinez, J. B., Valero, J. S., Bautista, A. J., Restrepo, J. F., Matteson, E. L., Rondon, F., \& Iglesias-Gamarra, A. (2007). Erosive arthropathy: clinical variance in lupus erythematosus and association with anti-CCP case series and review of the literature. Clinical and experimental rheumatology, 25(1), 47.

20. Benavente, E. P. I., \& Paira, S. O. (2011). Rhupus: report of 4 cases. Reumatología Clínica (English Edition), 7(5), 333-335.

21. ROY, P. C., \& PRADHAN, S. K. (2020). Rhupus Syndrome: An Overlap with Renal Complications. Journal of Clinical \& Diagnostic Research, 14(2).

22. Zhao, X. J., Wei, T., Dong, B., Jia, Y., \& Wang, M. (2015). Renal damage caused by Rhupus syndrome associated with anti-neutrophil cytoplasmic antibodies vasculitis and cryoglobulinemia. Beijing da xue xue bao. Yi xue ban= Journal of Peking University. Health Sciences, 47(5), 870-874.

23. Santos, R., Silva, R., Malvar, B., Pessegueiro, P., \& Pires, C. (2013). Proteinúria nefrótica num doente com Rúpus. Portuguese Journal of Nephrology \& Hypertension, 27(4), 295-299. 